\title{
OBESIDADE COMO FATOR DE RISCO NA PANDEMIA DA COVID-19
}

\author{
Hexael Demarch \\ Lisiane Tuon Generoso Bitencourt \\ DOI: http://dx.doi.org/10.18616/intcov26
}

Sabe-se que atualmente $20 \%$ da população adulta brasileira estão acima do peso, hoje a obesidade é um problema de saúde pública. A obesidade está relacionada a uma condição de acúmulo excessivo de tecido adiposo, que é um conjunto de doenças associadas, que explica a Síndrome metabólica. Ao entendimento o tecido adiposo é um órgão altamente ativo, perigo quando o acúmulo ocorre na região intra-abdominal. Essas alterações levam à presença de inflamação crônica de baixo grau, agredindo de forma importante o organismo. Em final de 2019, o mundo foi surpreendido com alta transmissibilidade o Sars-CoV-2, que vem infectando mais de um milhão de pessoas pelo mundo. A contaminação com o vírus intensifica o quadro inflamatório em resposta à infecção.

A obesidade tem se mostrado um dos fatores de risco, mais grave

\section{政}

do tipo M1 que secretam substâncias citocinas inflamatórias. As proliferações de citocinas inflamatórios (adipocitocinas) pelo tecido adiposo modificam diversos componentes, como atividade do sistema nervoso central, a área do hipotálamo que controla o apetite e saciedade, por meio da leptina. A modificação também de artérias e capilares, havendo o aumento da resistência vascular periférica e desajuste de monócitos e macrófagos do sistema imunológico, onde provêm as citocinas. Entrando no organismo humano o vírus Sars-CoV-2 se conecta às células para se multiplicar, tendo afinidade com a enzima Angiotensina II, caracterizada por ser uma enzima de membrana, multiplicada nos pulmões. Com o alojamento e afinidade do vírus, em reação de defesa, o corpo aumenta as citocinas. Um ambiente perfeito para proliferação inflamatória. 
Em resposta à obesidade abdominal, a repercussão é o aumento de citocinas sinflamatórias, como Interleucina- 6 (IL-6) e TNF-a (Fator de Necrose Tumoral Alfa) que inibem a lipase lipoproteíca, enzima que é responsável por degradar os triglicerídeos, havendo o aumento dos ácidos graxos livres, levando o aumento de NF-KB (Factor Nuclear Kappa B) um complexo protéico que desempenha funções como factor de transcrição, levando também o aumento da enzima ciclooxigenase II, que promove maior produção de prostaglandinas (inflamação) e tromboxanos (agregação plaquetária) formação de trombos. No processo de defesa do organismo ao vírus covid-19 há aumento de citocinas, interleucina-2 e interleucina-6, principais citocinas relevantes no quadro inflamatório do paciente. É pertinente considerar equivalentes citocinas secretadas.

O bloqueio da lipogênese, como resultado ocorre o aumento dos ácidos graxos livres e a secreção exacerbada de citocinas inibe inúmeros receptores com funções importantes. Essas resistências sensórias dos receptores levam a menor produção de macrófagos de leucócitos, com consequência decréscimo da função imunológica. Ocorre então o aumento de radicais livres, diminuição de antioxidantes, levando ao estresse oxidativo. Essa inflamação de baixo grau do obeso somando com o aumento exacerbado de citocinas potencializam a inflamação total do cometido. Explicando a causa da "Síndrome respiratória de falência dos múltiplos órgãos" ou "Tempestade imunológica da covid-19".

\section{OBRAS CONSULTADAS}

OUSSAADA, Sabrina M. et al. The pathogenesis of obesity. Metabolism Clinical and Experimental, Amsterdam, v. 92, p. 26-36, mar. 2019. Disponível em: https://doi.org/10.1016/j.metabol.2018.12.012. Acesso em: 10 jul. 2020.

SARDAR, Sindhu et al. Increased adipose tissue expression of Interferon Regulatory Factor (IRF)-5 in obesity: Association with Metabolic Inflammation. Cells, [s.l.], v. 8, n. 11, p. 1-22, nov. 2019. Disponível em: Doi: 10.3390/cells8111418. Acesso em: 10 jul. 2020. 